\title{
Çocukluk Çağı Zehirlenme Olgularının Epidemiyolojik Ve Demografik Özelliklerinin İncelenmesi
}

Evaluation Of Epidemiological And Demographic Features Of Childhood Poisoning Cases

Şenay Güven Baysal ${ }^{1}$, Feyza Mediha Yıldız ${ }^{2}$

1 Çocuk Sağı̆̆ı ve Hastalıkları Bölümü, Uşak Üniversitesi Eğitim ve Araştırma Hastanesi, Uşak/Türkiye

2 Çocuk Sağlığı ve Hastalıkları Bölümü, İstanbul Zeynep Kamil Kadın ve Çocuk Hastalıkları Eğitim ve Araştırma Hastanesi, İstanbul/Türkiye

\section{ÖzeT}

AMAÇ: Bu çalışmada Zeynep Kamil Kadın ve Çocuk Hastalıkları Eğitim ve Araştırma Hastanesi Çocuk Kliniği acil servisinde adli nitelikteki zehirlenme olgularının epidemiyolojik ve demografik özelliklerinin incelenmesi ve alınabilecek önlemlerin irdelenmesi amaçlanmıştır.

GEREÇ VE YÖNTEM: Acil servise başvuran ve zehirlenme nedeniyle hastaneye getirilen her bir hastanın bilgileri hasta takip formu aracılığıla belgelendirildi ve kaydedildi. Olgular yaş, cinsiyet, zehirlenme nedeni, mevsimsel dağılım, başvuru saati ve başvuruda zehirlenmeye ait semptomlar açısından değerlendirildi.

BULGULAR: Çocuk acil servisine başvuran hastaların \%0.21'ini zehirlenme vakası oluşturmaktaydı. Toplam 138 olgudan 72 'si erkek (\%52.2), 66’sı kız (\%47.8) hastalardan oluşuyordu. Vakaların \%87.7’sini 1-5 yaş arası hastaların oluşturduğu saptanmıştır. Zehirlenmeye en sık yol açan ilaçların başında \%25.6'ık oranla analjezik antipiretik ilaçları gelmekteydi. Hastaların \%18.8'in zehir danışma merkezi hakkında bilgi sahibiyken bu merkezin aranma oranı çalışmamızda \%8 olarak tespit edilmiştir. Olguların çoğu \%87.7 kaza ile meydana gelmişti. Intihar girişimi nedeniyle zehirlenmeler tüm olguların \%6.5'ini oluşturuyordu. Intihar amaçlı zehirlenme vakalarında kızların oranı belirgin bir şekilde yüksekti. (\%88.8). Olguların \%90'ı şifa ile taburcu edilirken \%7'si ailesi tarafından çıkarıldı ve \%3’ü yoğun bakıma sevk edildi.

SONUÇ: Çocuk acil servisine başvuran hastalardan elde ettiğimiz veriler daha önce yapılan çalışmalarla benzerlik göstermektedir. Öncelikle eğitim düzeyinin arttırılmasının zehirlenmelerin önlenmesine önemli ölçüde katkı sağlayacağı düşünülmektedir. Ayrıca hekimler tarafından Zehir Danışma Merkezinin aranması ve merkezin önerilerinin uygulanması da mortalite ve morbidite oranını azaltacaktır.

Anahtar Kelimeler: Zehirlenme, Çocukluk dönemi, Epidemiyoloji, Demografi

\section{ABSTRACT}

OBJECTIVE: In the present study, it is aimed to investigate the epidemiologic and demographic characteristics of the poisoning in children in criminal cases which were applied to Zeynep Kamil Women and Children Diseases Education and Research Hospital Pediatric Clinic with emergency.

MATERIALS AND METHODS: The information of the patients who has applied to our hospital were documented and saved through patient follow-up form. The cases were evaluated for age, sex, cause of poisoning, seasonal distribution and symptoms at application.

RESULTS: The rate of the Intoxications was \%0.21 of the whole child patients admitted to emergency service. There were 72 boys (\%52.2) and 66 girls (\%47.8) of total 138 patients. In the \%87.7 of the cases the ages of the patients were between 1 to 5. The most common drugs causing poisoning was antipyretic analgesic drugs with a ratio of $25.6 \% . \% 18.8$ of the patients were aware of the poison information center but only $\% 8$ of them called this center. Most accidents with $87.7 \%$ of cases had occurred by accident. Poisonings due to suicide was constituted the \% 6.5 of all cases. In cases of suicidal poisoning the proportion of girls were markedly higher (88.8\%). While $90 \%$ of patients were discharged home $\% 7$ of them was removed by the family and $3 \%$ of them were transferred to the intensive care unit.

CONCLUSION: The data obtained from patients applied to the pediatric emergency service were comparable with previous studies. It is being thought that increasing the level of education will prevent the poisoning significantly. Additionally, recommendations of poisoning control center and implementation of them by doctors will also reduce the mortality and morbidity rates

Key Words: Poisoning, Childhood, Epidemiology, Demography

Yazışma Adresi/Address for Correspondence: Şenay Güven Baysal, Uşak Üniv. Eğitim ve Araştırma H. Çocuk Sağlığı ve Hastalıkları Bölümü Uşak/Türkiye E-Posta/E-Mail: senay177@yahoo.com || Tel: +90 2762410000 (6104)

Received/Geliş Tarihi: 6 Tem 2018 || Accepted/Kabul Tarihi: 2 Ağu 2018

Bu Eser Creative Commons Atıf-Gayriticari 4.0 Uluslararası Lisansı Ile Lisanslanmıştır. This work is licensed under a Creative Commons

Attribution-NonCommercial 4.0 International License (CC BY-NC 4.0). 


\section{GiRiş}

Zehirlenme toksik bir maddenin vücuda zarar verecek miktarda ve değişik yollardan alınması sonucu organizmada bazı belirti ve bulguların ortaya çıkmasıdır (1).

Zehirlenmeler her yaş grubunda olmakla birlikte, çocukluk yaş grubunda daha sık görülmektedir. Amerikan Zehir Denetim Merkezleri Birliği, Zehirli Maddelere Maruziyet Gözetim Sistemi 2008 Yılı Raporuna göre 2.5 Milyon zehirlenme olgusunun \% 64.76'sını 0-19 yaş aralığındaki çocuk ve adölesan dönemdeki olgular oluşturmaktadır (2). Türkiye'de ise Refik Saydam Hıfzıssıhha Merkezi Başkanlığı'na bağlı Ulusal Zehir Merkezi'ne 2000-2004 yılları arasında yapılan başvuruların \%56'sını çocukluk çağı zehirlenme vakaları oluşturmaktadır (3).

Zehirlenmeye neden olan etkenler ülkeden ülkeye, aynı ülke içinde bölgeden bölgeye, hatta aynı bölgede zaman içinde bile değişebilir. Bunun yanında zehirlenme etkenleri yaşa, cinsiyete, ailenin eğitim düzeyine, yaşanılan bölgenin sosyokültürel yapısına göre de değişebilir. Bu nedenle her ülke ve bölge kendi zehirlenme profilini belirlemeli, buna göre karşı karşıya kaldığı risk ve tehditler için gerekli önlemleri almalıdır. Bu noktada zehir danışma merkezlerine de büyük iş düşmektedir.

Çalışmamızın amacı, çocukluk çağının sık karşılaşılan ve önlenebilir sağlık sorunlarından biri olan zehirlenmelerde, demografik ve epidemiyolojik özellikleri belirli bir süre zarfında kaydedip analiz etmek, olayın öncesi ve sonrasındaki çevresel ve ailesel etkenlerin rolünü araştırmaktır..

\section{GEREÇ VE YÖNTEM}

Çalışma Zeynep Kamil Kadın ve Çocuk Hastalıkları Eğitim ve Araştırma Hastanesi Çocuk Kliniği acil servisinde yapıldı. Zehirlenme nedeniyle başvuran 0-18 yaşlarındaki çocuk hastalar çalışmaya dahil edildi. Koroziv madde ve besin zehirlenmeleri çalışmaya dahil edilmedi.

$\mathrm{Bu}$ tarihler arasında zehirlenme nedeniyle hastaneye getirilen her bir hastanın; çocukların demografik özellikleri, yatış tarihi, çocuk acile başvuru saati, zehirlenme ile sağlık kurulusuna başvuru arasında geçen süre, hastanemiz öncesi başka bir sağlık kuruluşuna başvuru durumu, hastanemize başvurmadan önce evde veya başka sağlık kuruluşunda yapılan müdahaleler, zehir danışma merkezinin bilinirliği ve aranıp aranmadığı, alınan toksin veya toksinlerin cinsi, miktarı, toksinin alım yeri, toksinin alım yolu, intihar amaçlı olup olmadığı, başvuruda zehirlenmeye ait semptom durumu, hastanın kronik hastalık durumu, hastanemizde yapılan tedaviler ve hastaların hayatta kalma durumu zehirlenme olgularında hasta takip formu aracıllı̆ıyla belgelendirildi ve kaydedildi. Çalışma Zeynep Kamil Kadın ve Çocuk Hastalıkları Eğitim ve Araştırma Hastanesi Etik Kurulunun 12.05.2008 tarih ve 24 numaralı onayı ile yapıldı. Çalışmaya alınacak hastalar için ailelerden aydınlatılmış onam alındı.

Toplam 138 adet hastanın verileri çalışmaya dahil edildi..

\section{BULGULAR}

Zehirlenme nedeniyle başvuran hastalardan 66'sı kız (\%48), 72'si erkek (\%52) olmak üzere toplam 138 hasta çalışmaya dahil edilmiştir. Kaydı yapılan bu 138 olgunun yaş ortalaması $3.6 \pm 3.43$ (6 ay - 17 yaş). Zehirlenmelerin yaş grupları bakımından dağııımlarına bakıldığında 1-4 yaş (En sık: 2,5 yaş) aralı̆̆ında bir zirve yaptığı tespit edilmiştir. Zehirlenmelerin zirve yaptığı 1-4 yaş grubunda erkeklerin kızlardan fazla olduğu görülmüştür. Çalışmamızda hastaların \% 72,4'ü 1-4 yaş grubunda toplanmıştır. Vakaların \%86,2'si 6 yaş altındadır. Okul öncesi dönemdeki çocuklarla ( $n=120, \% 86,9)(66$ 'sı erkek, 54'ü kız) karşılaştırıldığında okul çocuklarında ( $n=15, \% 13,1)$ kız çocukları daha ön plandaydı (6'sı erkek, 9'u kız) (Grafik 1).

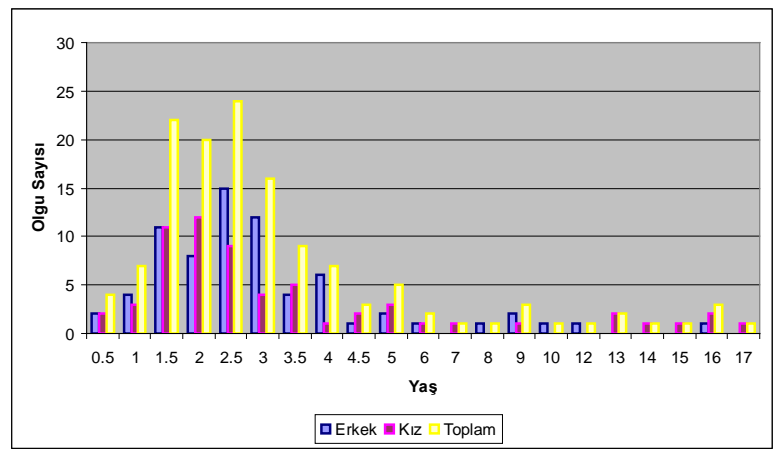

Grafik 1: Zehirlenme olgularında yaş ve cinsiyet dağılımı

Zehirlenme olayı en çok evde gerçekleşmiştir. 138 olgudan 122 tanesi (\%88) evde gerçekleşirken 10 tanesi (\%7) başka bir evde gerçekleşmiştir. Toplam 6 adet ( \%4) vaka ise dışarıda gerçekleşmiştir. 138 olgudan 121 'inde (\% 88) tek etkenle zehirlenme görülürken 17 olguda (\%12) çok etkenle zehirlenme görülmüştür.

Zehirlenmenin oluş şekli olarak değerlendirildiğinde tüm olguların içerisinden 121 tanesi (\%88) kaza ile gerçekleşirken 9 olgu (\%7) intihar amaçlı gerçekleşmiş, 8 
olgu da (\%6) terapötik hata nedeniyle meydana gelmiştir (Grafik 2). Intihar amacıyla ilaç alan olguların \%89'u adölesan kız çocuklarıydı. Ortalama yaşları 14,12 $\pm 2,53$ yıldı (9-17 yaş, median değer: 14.5 yaş) (Grafik 2).

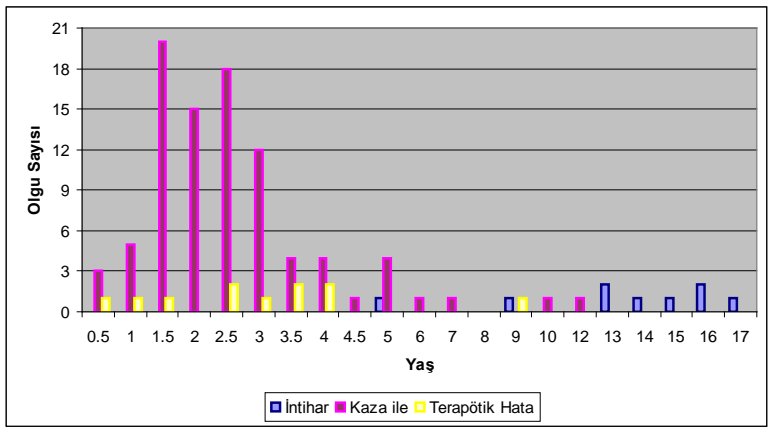

Grafik 2: Zehirlenme olgularının yaş ve zehirlenme sebebi bakımından dağııııı

Olguların tamamında zehirlenme ilaç alımıyla gerçekleşmişti. 62 olguda (\%54) etken kendine ait kutuda bulunuyorken 10 olguda (\%9) kendine ait olmayan bir kutuda bulunuyordu. 43 adet olguda (\%37) ise etken açıkta bulunuyordu. 138 olgudan 84'ünde (\%61) hastada herhangi bir yakınma bulunmazken, 21 olguda (\%15) kusma, 11'inde (\%8) bulantı, 8'inde (\%6) karın ağrısı ve 16'ünde (\%10) diğer başka belirtiler görülmüştür. 131 olguda tek ilaç (\%94) ve 7 olguda çoklu ilaç (\%6) zehirlenmesi söz konusuydu. Zehirlenmeye en sık yol açan ilaçların başında analjezik antipiretik ilaçlar (\%25.6) gelmektedir. Bunu sırasıyla GiS (\%17.4) ve SSS (\%14) ilaçları takip etmektedir (Grafik 3).

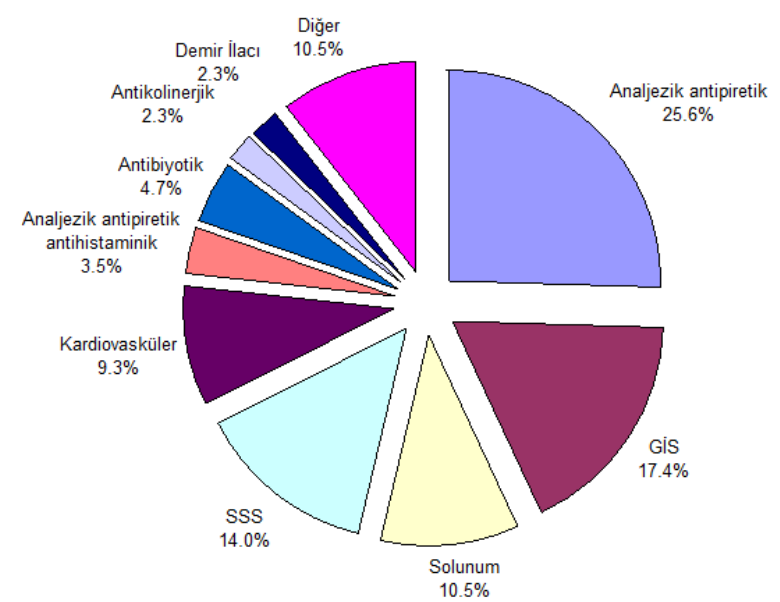

Grafik 3: Zehirlenmeye neden olan ilaçların dağılımı

11 adet olguda (\%11), ( $\mathrm{n=103)}$ hastanın ailesinde geçmişte zehirlenme öyküsü var iken 92 olguda (\%89) ailede bir zehirlenme öyküsü yoktur. Zehirlenme nedeniyle hastaneye başvuru en yüksek 20:00-23:00 saatleri arasında olmuştur

\section{TARTIŞMA}

Amerikan Zehir Denetim Merkezleri Birliği, Zehirli Maddelere Maruziyet Gözetim Sistemi 2008 Yılı Raporuna göre 2.5 Milyon zehirlenme olgusunun \% 64.76'sını 0-19 yaş aralığındaki çocuk ve adölesan dönemdeki olgular oluşturmaktadır (2). Türkiye'de ise Refik Saydam Hıfzıssıhha Merkezi Başkanlığı'na bağlı Ulusal Zehir Merkezi'ne 2000-2004 yılları arasında yapılan başvuruların \%56'sını çocukluk çağı zehirlenme vakaları oluşturmaktadır (3).

Yapılan çalışmalarda zehirlenmeye bağlı acil servis başvurularının oranları \%0,076-0,7 arasında değişmektedir (4). Türkiye'de Devlet istatistik enstitüsü verilerine göre 1995 yılında ülkemizdeki zehirlenme prevalansının \% 0.4 olduğu bildirilmiştir. Ülkemizde yapılan diğer çalışmalarda zehirlenme olgularının acil servise başvuran tüm olguların \%0.46 ila \%1.57'sini oluşturduğu gözlenmiştir (100). Bizim analizimizde bu oran \%0.21 olarak saptanmıştır. Bu farkın sebebi bizim analizimizin koroziv maddeleri ve besin zehirlenmesi olgularını kapsamamasından ileri gelmektedir.

Çalışmamızda zehirlenme olgularına yaş dağılımı olarak baktığımızda 1-5 yaş arasında bir zirve görülmektedir (\%81). $\mathrm{Bu}$ oran, Biçer ve arkadaşlarının çalışmasında \%65, Özdemir'in çalışmasında \%56.1, Şenel'in çalışmasında \%55,8, Öntürk'ün serisinde \%65 olarak bildirilmiştir. Bunun sebebi, bu yaştaki çocukların çok hareketli, araştırmacı, öğrenme merakının çok olması ve her bulduğu maddeyi ağzına alarak tanımaya çalışmasından kaynaklanmaktadır $(5,6,7,8)$. Bunun yanında hem Biçer'in serisinde hem de bizim serimizde 12-19 yaş arasındaki grupta kız çocuk baskınlığı dikkat çekmektedir. Oranlar \%75 ile \%77'dir (6).

Ülkemizde zehirlenme olasılığını arttıran unsurların başında küçük çocukların evde sık sık yalnız, kardeşiyle ya da arkadaşıyla bırakılması, ilaçların ve temizlik maddelerinin çocukların rahatça ulaşabileceği yerlerde bulunması yer almaktadır. Ayrıca ailelerin eğitim seviyelerinin düşük olması ve bilinçsiz olmaları da bunu destekleyen bir nedendir. Eğitim düzeyinin arttırılması, ilaçların ve temizlik maddelerinin korumalı ambalajlarda paketlenmesi ve özellikle temizlik malzemelerinin kendi ambalajında tutulmasının zehirlenmeleri önemli ölçüde azaltılacağı düşünülmektedir. 
Amerikan Zehir Denetim Merkezleri Birliği, Zehirli Maddelere Maruziyet Gözetim Sistemi 2008 Yılı Raporuna göre zehirlenmelerin \%93.4'ü evde gerçekleşmiştir. Bizim çalışmamızda oran \% 95.7 olarak Amerika'dakine oldukça yakın bulunmuştur. Penbegül'ün analizinde bu oran $\% 80$ iken Özdemir'in çalışmasında \%92 olarak bildirilmiştir. Analizimizde gerçekleşen sonuçların hem ulusal hem de uluslararası çalışmalarla uyumlu olduğu görülmektedir $(2,5,9,10)$.

Çalışmamızda zehirlenmeye neden olan ilaçlar arasında 2. en sık görülen ise GiS ilaçlarıdır. Bizim çalışmamızda bu oran \% 17.4 iken Özdemir'in analizinde \% 3, Güzel'in analizinde ise \% 5.9 olarak bildirilmiştir. Bizim çalışmamızda diğer çalışmalara göre daha yüksek oranda Gis ilacı ile zehirlenme olgusu görülmüştür. Analizimizdeki tüm Gis ilacıyla zehirlenme olgularında ilaçlar hastaların ebeveynlerine aitti. Bilindiği üzere toplumda hızla artan reflü ve ülser hastalıklarının görülmesi Gis ilaçlarına olan talebin ve ihtiyacın her geçen gün artması ile bu ilaçlar evlerde daha çok bulundurulmaktadır. Çalışmamızda Gis ilacı ile olan zehirlenmelerin diğer çalışmalara göre daha yüksek çıkmasının bu nedenlerden dolayı olduğu düşünülmektedir $(5,9)$.

Zehir danışma merkezleri önemli bir tıbbi bilgi kaynağı olarak hizmet vermekte olup zehirlenme olaylarında morbidite, mortalite ve tedavi maliyetlerini azaltmayı da hedeflemektedirler. Bu anlamda örneğin Amerika'da 60 adet zehir danışma merkezi olup bunlar 7 gün 24 saat hizmet vermektedir. Ülkemizde de 2 tane haftanın 7 günü 24 saat hizmet veren ve 2 tane de mesai saatlerinde çalışan toplam 4 adet ilaç ve zehir danışma merkezi bulunmaktadır.

Zehirlenmelerin tedavisi yapılırken danışmanlık bilgileri veren zehir danışma merkezleri hastanemiz hekimleri tarafından tüm zehirlenme vakalarında istisnasız aranmakta ve önerileri alınmaktadır. Bu merkezlere ait iletişim bilgileri faydalı olacağı düşünülerek Tablo 1'de verilmiştir (11).

Çalışmamızda 2 cıva zehirlenme vakası mevcuttur. Bu olgularda zehirlenme, çocukların cam termometreyi ağzına götürmesi suretiyle ağzında kırılması ve civanın inhalasyon yoluyla alınması sonucu gerçekleşmiştir. Gerekli tedaviler yapılmış ve hastalar taburcu edilmiştir. Bu iki olgu yakın zamanda Sağlık Bakanlığı'nın cıvalı termometre satışının yasaklanması konusunda verdiği kararın doğruluğunu desteklemektedir.

Tablo 1: Türkiye'deki zehirlenme merkezleri ve iletişim bilgileri

\section{7-24 Hizmet veren merkezler}

- Refik Saydam Hıfzıssıhha Merkezi Başkanlığı Ulusal Zehir Danışma Merkezi (Türkiye'nin her yerinden 114 numaralı telefon ile ulaşılabilir.)

- Uludağ Üniversitesi İlaç ve Zehir Danışma Merkezi (0224-442 82 93)

Mesai saatleri içinde hizmet veren merkezler

- Hacettepe İlaç ve Zehir Bilgi Merkezi (HizBiM) (0-312 31189 40) (0312 30521 33-34)

- Dokuz Eylül Üniversitesi Tıp Fakültesi İlaç ve Zehir Danışma Merkezi (0-232-412 3939)

Olgularımızda bulantı, kusma, karın ağrısı en sık görülen belirtiler olarak saptanmıştır. Sonuçlarımız Güzel'in analizi ile Öntürk ve arkadaşlarının çalışmasına benzerlik göstermektedir. Bu nedenle özellikle ani başlayan ve yukarıdaki semptomları gösteren klinik tablolarda zehirlenme de ayırıcı tanımızda mutlaka yer almalıdır. Olgularımızdan \%60.9'unda başvuru esnasında herhangi bir yakınma görülmemiştir. Asemptomatik başvuruların oranının yüksek olması, hastaların servisimize semptomlar ortaya çıkmadan kısa sürede (ortalama 2 saat) başvurmalarından kaynaklanmaktadır.

Hastaların büyük bir kısmı sosyal güvenlik kurumlarından birine bağlıydı (\%88). \%12'sinin ise herhangi bir sağlık güvencesi bulunmamaktaydı. Zehirlenmelerin $\% 92,8^{\prime} i$ oral yolla meydana gelmişti. Bunu sırasıyla, solunum (\%3.6), deri ve mukoza yolu (\% 1.4) ile olan zehirlenmeler izlemekteydi. Oral yoldan meydana gelen zehirlenme oranı Özdemir'in retrospektif analizinde \%92.5, Güzel'in analizinde ise $\% 75.8$ olarak belirtilmiş ve çalışmamızda olduğu gibi ilk sırayı almıştır $(5,9)$.

Olgularımızın \% 51.4'üne mide yıkama, \%53.6'sına aktif kömür, \%5.7'sine antidot ve \%68.1'ine de genel destek tedavisi uygulandı. Bu oranlar Özdemir'in analizinde mide yıkama \%57.5, aktif kömür verme \%52.5, antidot verme $\% 11.1$ ve destek tedavisi \%15 olarak bildirilmiştir. Hastalarımızın \%32'si acil serviste, \%57'si serviste yatırılarak tedavileri uygulandı. 11 olguda hasta, ailesi tarafından tedavi süresi dolmadan çıkarıldı. 3 olguda yoğun bakıma intiyaç duyuldu (5). Kamış'ın analizinde acil serviste gözlenen olguların oranı \%25.5 iken hastaların \% 27.1'inin 
serviste yatırılarak takip edildiği bildirilmiştir. Hastanemizde tüm zehirlenme vakalarında zehir danışma merkezi aranmakta ve önerilen tedaviler uygulanmaktadır. ZDM'nin önerdiği takip süresi 24 saatten az ise hastalar acil serviste müşahede altında tutulmakta 24 saatten fazla ise servise yatırılmaktadır. Bizim çalışmamızda acil serviste gözlenen olguların oranını yüksek çıkmasının sebebi bu şekilde açıklanabilir. Ayrıca bu durum ZDM'yi aramanın hastanelerde gereksiz yatak işgalini önlediği ve iş gücü kaybını önlediğinin de bir göstergesi olmuştur (12).

Zehirlenmeye bağı ölüm oranı gelişmiş ülkelerde \%1 seviyelerinde iken gelişmekte olan ülkelerde bu oran \%3 $\% 5$ arasındadır $(13,14)$. ABD zehir kontrol merkezinin çalışmalarında bu oran \%0,036 olarak bildirilmiştir (15). Ülkemizde de farkı bölgelerde yapılan çalışmalarda farklı rakamlar saptanmıştır. Karadeniz bölgesinde \%3.9, Isparta'da \%0.3 ve Trakya bölgesinde de \%.1,5 olarak belirlenmiştir $(15,16)$. Yapılan başka bir araştırmada acil servislere başvuran zehirlenme sayısında ilerleyen yıllarla birlikte bir artış olmasına rağmen, tanıyı kolaylaştıracak olanakların artması, ve tedavideki önemli gelişmelerden dolayı ölüm oranı 1960'lı yıllardan sonra düşmeye başlamıştır (11). Öntürk ve arkadaşlarının yaptığı çalışmada mortalite \%0.6, Andıran ve arkadaşlarının yaptığı çalışmada \%0.4, Uçar ve arkadaşlarının yaptığı çalışmada ise \%3.9 olarak bildirilmiştir $(8,16)$. Biçer ve arkadaşları ile Bucak ve arkadaşlarının çalışmalarında ise ölüm oranını \%0 olarak bildirilmektedir $(6,17)$. Bizim çalışmamızda da zehirlenme nedeniyle ölüm gözlenmemiştir ve Biçer'in çalışması ile benzerlik göstermektedir. Bunun sebebi ileri düzeyde ağır zehirlenme vakalarının genel olarak acil servisten daha donanımlı yoğun bakım üniteleri olan diğer hastanelere sevk edilmesiyle birlikte, hastanemizde de etkin izlem ve tedavi yöntemlerinin uygulanmasından kaynaklandı̆̆ı düşünülebilir. Ayrıca tüm zehirlenme olgularında hekimlerimizin Zehir Danışma Merkezini araması ve merkezin önerilerinin uygulanmasının da mortalite oranını azalttı̆̆ı düşünülmektedir.

Çocukluk çağı zehirlenmeleri çocuk acil olguları arasında önemli bir yer tutmaktadır. Zehirlenmeler önlenebilir vakalar olduğundan hem birey hem de toplum bu konuyla ilgili bilinçli olmalı ve gereken önlemleri almalıdır. Küçük çocukların genelde evde yalnız ya da kardeşiyle bırakılmaları, ilaçların yada toksik maddelerin kolayca ulaşılabilecek yerlerde olması zehirlenmelere davetiye çıkarmaktadır. Bu konuda aileler çok dikkatli olmalıdırlar. Ailelerin eğitim düzeyi ve bilincinin arttırılması, ilaç üreticilerinin çocuk kilitli ilaç kapağı uygulamalarını yaygınlaştırması zehirleme oranlarını düşürecektir. Çalışmamızın sonucu olarak toplumda zehir danışma merkezinin bilinirlik oranının yükseldiği gözlenmiştir. Bu olumlu bir gelişmedir. Zehir danışma merkezlerinin yaygınlaştıııması hekimlerimize tanı ve tedavide yol gösterici olacaktır. Ayrıca Amerika'da 1983 yılından beri yapıldığı gibi yıllık zehirlenme raporlarının bu merkezler tarafından yayınlanması faydalı olabilir. Bu rapordaki bilgilerle bazı riskler ve tehlikeler daha erken tespit edilebilir, bunları önlemek için eğitimler düzenlenebilir ve aynı zamanda klinik araştırmalar da yapılabilir. Çalışmamızın çocukluk çağı zehirlenme vakalarını azaltmak için gereken önlemlerin alınması konusunda yol gösterici olacağını umut ediyoruz.

Çocuk acil servisine başvuran hastalardan elde ettiğimiz veriler daha önce yapılan çalışmalarla benzerlik göstermektedir. Öncelikle eğitim düzeyinin arttırımasının zehirlenmelerin önlenmesine önemli ölçüde katkı sağlayacağı düşünülmektedir. Ayrıca hekimler tarafından Zehir Danışma Merkezinin aranması ve merkezin önerilerinin uygulanması da mortalite ve morbidite oranını azaltacaktır.

Yazarlar arasında çıkar çatışması yoktur.

The author declares no conflict of interest.

Finansal Destek: yoktur / Funding : none

doi: $* * * * * * * * * * * * * *$

\section{KAYNAKLAR}

1. Arısoy N, Aji DY. Zehirlenmeler. Onat T (ed). Çocuk Sağlığı ve Hastalıkları: Cilt 2, Eksen Yayınları, istanbul 1996; 1037-1055.

2. Bronstein AC, Spyker DA, Cantilena LR Jr, Green JL, Rumack BH, Giffin SL. 2008 Annual Report of the American Association of Poison Control Centers' National Poison Data System (NPDS): 26th Annual Report.

3. Geçim NO, İincioğulları D, Harmancı N. Ulusal Zehir Merkezi'ne yapılan çocukluk çağı vaka başvurularının değerlendirilmesi: 5 yıllık retrospektif çalışma. Türkiye Klinikleri J Pediatr Sci 2006, 2(5):1-4.

4. Bronstein AC, Spyker DA, Cantilena LR Jr, Green JL, Rumack $\mathrm{BH}$, Heard SE; American Association of Poison Control Centers. 2007 Annual Report of the American Association of Poison Control Centers' National Poison Data System (NPDS): 25th 
Annual Report. Clin Toxicol (Phila) 2008;46:927-1057.

5. Özdemir R. Zehirlenmeler ve Hacettepe deneyimi. Katkı Pediatri Dergisi 2009 :47-68.

6. Biçer S, Sezer S, ve ark. Çocuk Acil Kliniği 2005 Yılı Akut Zehirlenme Vakalarının Değerlendirilmesi. Marmara Medical Journal 2007; 20(1): 12-20.

7. Şenel Güzel I, Esin Kibar A, Vidinlisan S. Ankara Dışkapı Çocuk Hastalıkları Eğitim ve Araştırma Hastanesi çocuk acil servisine başvuran zehirlenme vakalarının demografik özelliklerinin incelenmesi. Genel Tıp Dergisi 2011;21(3):101-107.

8. Akbay-Öntürk Y, Uçar B. Eskişehir Bölgesinde çocukluk çağı zehirlenmelerinin retrospektif değerlendirilmesi. Çocuk Sağ|ı̆ı ve Hastalıkları Dergisi 2003; 46:103-113.

9. Güzel I.Ş Ankara Dışkapı çocuk hastalıkları eğitim ve araştırma hastanesi çocuk acil servisine ekim 2006 ekim 2007 tarihleri arasında başvuran zehirlenme vakalarının demografik özelliklerinin incelenmesi - Uzmanlık Tezi - İstanbul 2007.

10. Penbegül L. Ilaç Zehirlenmesi olan Çocuk Olgularda Demografik Özellikler ve Ailesel Etkenlerin Değerlendirilmesi. Uzmanlık Tezi - İstanbul 2006.

11. Gürpınar $T$, Aşırdizer $M$, Zehirlenmelerde Hekim Sorumluluğu, Türkiye Klinikleri J Surg Med Sci 2006, 2(50):56-62).

12. Kamış M. Sami Ulus hastanesi çocuk acil servisine başvuran adli olguların iki yıllık sürede değerlendirilmesi Uzmanlık Tezi Ankara 2008.

13. Wolf AD. Poisoning in children and adolescents. Pediatr Rev 1993; 14: 411-422

14. Uçar B, Ökten A, Mocan H. Karadeniz bölgesinde çocuk zehirlenme vakalarının retrospektif incelenmesi. Çocuk Sağlığı ve Hastalıkları Dergisi 1993; 36: 363-371

15. Litovitz TL, Klein-Schwartz W, Caravati EM, Youniss J, Crounch B, Lee S. Annual report of the American Association of Poison Control Centers Toxic Surveillance System. Am J Emerg Med 1999; 17: 435-487

16. Andıran N, Sarıkayalar F. Hacettepe Üniversitesi îhsan Doğramacı Çocuk Hastanesinde son 6 yılda izlenen akut zehirlenme vakaları. Katkı Pediatri Dergisi 2001; 22: 396-408.)

17. Bucak i H, Turgut $M$, Tümgör $G$, Eynallı A. Çukurova Bölgesinde Üçüncü Basamak Bir Hastanede 2006-2010 Yılları Arasında Çocukluk Çağı Ilaç Zehirlenmelerinin Değerlendirilmesi. Türkiye Çocuk Hastalıkları Dergisi 2015;2:124-130 